\title{
Skin Response Planned Time Point Name
}

National Cancer Institute

\section{Source}

National Cancer Institute. Skin Response Planned Time Point Name. NCI Thesaurus.

Code C117694.

The literal identifier of a planned point in time for a skin response assessment. 